
(Anadolu Çevre ve Hayvanculık Bilimleri Dergisi) DOI: https://doi.org/10.35229/jaes.941471

\title{
Baraj Deformasyonları ve Al Kut Barajı (Irak) Örneği ${ }^{[*]}$
}

\author{
Mukhalad Sahib Hammoodi AL-JASSANi ${ }^{1}$ Nükhet KONUK ${ }^{1 *}$ \\ ${ }^{1 *}$ Ondokuz Mayls Üniversitesi, Mühendislik Fakültesi, Harita Mühendisliği Bölümü, 55270, Samsun, Türkiye
}

Atıf yapmak için: Konuk, N. \& AL-JASSANi, M.S.H. (2021). Baraj deformasyonları ve Al Kut Barajı (Irak) örneği. Anadolu Çev. ve Hay. Dergisi, 6(3), 456-461.

How to cite: Konuk, N. \& AL-JASSANI, M.S.H. (2021). Dam deformations and the Case of Al Kut Dam (Iraq). J. Anatolian Env. and Anim. Sciences, 6(3), $456-461$.

: https://orcid.org/0000-0001-6099-4850 iD : https://orcid.org/0000-0002-9041-5570

Sorumlu yazarın:

Nükhet KONUK

Ondokuz Mayıs Üniversitesi, Mühendislik

Fakültesi, Harita Mühendisliği Bölümü,

55270, Samsun, Türkiye

$凶:$ nukhetg@omu.edu.tr
Öz: Deformasyon ölçümleri, yoğun nüfuslu yerleșim alanlarında en önemli mühendislik etüt faaliyetlerinden biridir. Mühendislik yapıları, tektonik hareketler, heyelanlar ve yeraltı suyu seviyesi gibi faktörler nedeniyle ya da ana kayadaki sıcaklık, yaşlanma ve diş etkenlerle deformasyona uğrarlar. Deformasyonların ölçümleri ve analizi, doğru araştırma ekipmanı ve doğru analiz yöntemlerinin kullanılmasını gerektirir. Hassas konumlandırmaya izin veren ve 24 saat yarı otomatik veri işleme sağlayan Küresel Navigasyon Uydu Sistemi (GNSS) araçları, deformasyon uygulamalarının izlenmesinde, yerkabuğunun yer değiştirmesinin hesaplanmasında yaygın olarak kullanılmaktadır. Bu çalıșmada, baraj deformasyonlarının sebepleri, deformasyon türleri ve deformasyon izlemede GNSS araçlarının kullanımı araştırılmıștır. Ayrıca baraj derformasyonları Irak'ta yer alan Al Kut Barajı örneğinde incelenmiştir. 2017 yılında yapılan ilk gözlem ile 2019 yılında yapılan son gözlem arasındaki düşey fark $0.00683 \mathrm{~m}$, mesafe farkı ise yatayda $0.0179 \mathrm{~m}$ olarak belirlenmiştir. Bu sonuçlara göre, hem yatay düzlemde hem de düşey düzlemde eşit olmayan farklılıklar gözlenmiştir.

Anahtar kelimeler: Baraj deformasyonu, deformasyon ölçümleri, küresel navigasyon uydu sistemi (GNSS), ölçme.

\section{Dam Deformations and the Case of Al Kut Dam (Iraq)}

\begin{abstract}
Distortion measurements are one of the most important engineering survey activities in densely populated residential areas. The engineering structures are submitted to deformation due to the various factors such as tectonic movements, landslides and groundwater level, or due to the temperature, aging and external factors. As a results of the deformation measurements are directly related to the integrity of engineering structures and human life. avoiding misinterpretation of the displacements, a suitable distortion monitoring network must be established, and the data received from the distortion monitoring network should be carefully evaluated. Distortion measurements and analysis require the correct research equipment and correct analysis methods. GNSS instruments, which enable extremely accurate positioning and provide 24-hour semi-automatic data processing, are widely used in monitoring deformation applications and calculating the displacement of the Earth's crust. In this study, the factors efecting dam deformations, the types of deformations and the use of GNSS tools in deformation monitoring were investigated detailed. In addition, dam deformations were examined in case of Al Kut Dam in Iraq. The vertical difference between the first observation made in 2017 and the last observation made in 2019 was $0.00683 \mathrm{~m}$, and the distance difference was $0.0179 \mathrm{~m}$ horizontally.According to these results, unequal differences were observed in both the horizontal and vertical planes..
\end{abstract}

Keywords: Dam deformation, deformation measurements, global navigate satellite system (GNSS), surveying.
Corresponding author's:

Ondokuz Mayıs University, Faculty of

, Department of Geomatic

Engineering, Samsun, Turkey

凶: nukhetg@omu.edu.tr 


\section{GíRiş}

İnsanlığın ihtiyacı olan içme ve kullanma suyu temini, sulama suyu, su ürünleri üretimi, enerji üretimi için barajlara gereksinim duyulmuştur. Mühendislik yapıları olan barajlardaki değişimin izlenmesi, belirlenmesi ve yorumlanması oldukça önem arz etmektedir. Baraj, tünel gibi mühendislik yapılarında çeşitli etkilerle oluşan boyut değişimlerine deformasyon, bu deformasyonların ölçüm yöntemleri ile belirlenmesine de deformasyon ölçümleri adı verilir (Yıldırım, 2007). Baraj, ülke ekonomisindeki önemli altyapılardan biri olarak tanımlanabilir ve ulaşım ağı, su depolama ve elektrik üretiminde önemli bağlantılara sahiptir (Jaafar, 2017).

Barajlar iç ve dış yüklerden etkilenmekte ve deformasyona uğramaktadır. Yükler sabit değildir ve zamanla değişiklik gösterebilmektedir. Bir tankın hidrostatik basıncı, barajın merkez hattına dik olarak kalıcı yatay deformasyona neden olabilmektedir (Okiemute vd., 2018). Barajın ağırlığı ve tankın hidrostatik basıncı gibi su kuvvetleri, yapıların düşey hareketine yol açmaktadır. Kaya dolgu barajda elastik davranış daha küçüktür (Galán vd., 2013; Taşçi, 2008).

Deformasyon türlerinin ana nedenleri olarak değişen sıcaklıklar (yazın ısınması ve kışın soğuması), doğal deformasyonlar (yer kabuğunun deformasyonları), depremler ve volkanlar sayllabilmektedir (Abdulkahdum, 2015). Depremler genellikle yeraltındaki kayanın aniden bir fay boyunca kırılmasiyla olmaktadır. Meydana gelen ani enerji salınımı, yerin sarsılmasına neden olan sismik faaliyetlere yol açmaktadır (Barzaghi vd., 2018). Sismik faaliyetler, levha sınırları düzeyinde gerçekleşmektedir (Al-Husseinawi vd., 2018). Ardından, oluşan basınç nedeniyle kayalar kırılarak deprem meydana gelmektedir (Burgmann ve Dresen, 2008). Deprem sirasinda veya sonrasında kaya plakaları veya blokları hareket etmeye başlamakta ve tekrar sıkışana kadar hareketine devam etmektedir (Jansen, 1983; Sêco e Pinto, 2010). Toprak dolgu ve kaya dolgu barajların depreme tepkisi, hareketin ivmesi ve hızına göre farklılık göstermekle birlikte, barajın jeolojik yapısına bağlıdır (Anastasiadis vd., 2004). İvme yeterince büyük olduğunda, sarsıntı geçici bir düşey harekete neden olmaktadır (Li vd., 2019). Baraj deformasyonlarında diğer bir kritik faktör de inşaat kalitesidir. Düşük derecede sıkışmaya sahip barajlar, depremlerde oldukça büyük zarar görebilmektedir.

Yeryüzü çeşitli hareketlere ve deformasyonlara maruz kaldığından, bu deformasyonları farklı ölçeklerde izlemek önem arz etmektedir (Abdullahi, 2016) . Jeodezik hesaplamalarla küresel levhaların hareketi ile temsil edilen jeodinamik mekanizmaları ölçmek mümkündür (Rodrigues vd., 2020).

Deformasyon iki şekilde belirlenebilmektedir. (i) bir, iki veya üç boyutlu yer değiştirme ya da coğrafi referanslı hareketleri ölçmek için Total Station, Nivo, Küresel Navigasyon Uydu Sistemi (GNSS) kullanımını içeren jeodezik ölçüm cihazları, (ii) yağ çubuğu, yüksek basınç ölçerler, yağmur ölçerler, termometre, barometre, eğim, ivme ölçer, deprem ölçer ve diğerleri gibi bazı araçların kullanımını içeren geoteknik ölçüm cihazları ile ölçülebilmektedir (Okiemute vd., 2018).

Barajlarda deformasyon, yapının boyutuna, türüne ve deformasyonun nedenine bağlıdır. Örneğin, yük altında veya yeni başlayan dengesizlik altında yapının temelinde deformasyona neden etkiler farklı büyüklük ve şekillerde olabilir (Moore, 1992). Yer değiştirme eğilimleri jeoteknik araçlardan tahmin edilerek inşaat projelerinde belgelenebilir (USACE, 2002).

Deformasyonların izlenmesinde farklı araçlar kullanılmaktadır. Literatürde bu araçlar ile ilgili farklı sinıflandırmalar mevcuttur. Örneğin Moore (1992), dikey hareketler, eğim (şakül dişı), yatay hareketler ve çatlaklar gibi ölçümlerin türüne göre izleme yaklaşımlarının ilkesini belirlemiştir. Düşey hareketler için hassas tesviye, eğim için lazer sistemi ve hassas optik şaküller, yatay hareketler ve GNSS sistemleri için teodolit ve Elektronik Mesafe Ölçüm Cihazları (EDM) önerilmiştir.

Hill ve Sippel, (2002), deformasyon izlemede kullanılan aletleri etüt, jeoteknik ve meteorolojik olarak üç gruba ayırmıştır. Hill ve Sippel (2002)'e göre tek boyutlu ölçümler jeoteknik ve meteorolojik aletlerle sağlanabilirken, üç boyutlu ölçümler, ölçme sensörleri kullanılarak yapılmaktadır. Ölçme yöntemi için olarak Total Station ve GNSS üzerine odaklanılmıştır. Ekstansometreler, eğimölçerler, piyezometreler, gerinim ölçerler, basınç hücreleri, eğim sensörleri ve çatlak ölçerler gibi jeoteknik sensörler izleme için yaygın olarak kullanılmaktadır. Meteorolojik aletler; sıcaklık, bağıl nem, barometrik basınç, rüzgâr hızı, rüzgâr yönü, küresel radyasyon (güneş enerjisi) ve yağış hakkında veri toplarken genellikle diğer sensörleri kalibre etmek için kullanılmaktadır.

USACE, (2002) ve Kalkan vd., (2010) ise izleme sensörlerini jeodezik sensörler ve jeodezik olmayan (jeoteknik) sensörler olmak üzere iki gruba ayırmıştır. Buna göre jeodezik yöntemlerde hassas teodolitler, lazer optik, Elektronik Mesafe Ölçüm Cihazları (EDM), Küresel Konumlandırma Sistemi (GPS), GLONASS ve GALILEO alıcıları, lazer tarayıcılar; jeodezik olmayan yöntemlerde ise eğimölçer, yerleşim sütunu, ekstansometre, piyezometre, ters sarkaç kullanılmaktadır.

Park vd., (2007) yaptıkları çalışmada; işlevsel olarak izlemede kullanılan sensörleri gruplandırmışlardır. Güvenliği kontrol etmek ve servis kolaylığı sağlamak için kullanılan sensörler, gerinim ölçerler gibi güvenlik sensörleri, ivmeölçerler ve GNSS gibi servis verilebilirlik 
sensörleridir. Bununla birlikte, fotogrametri teknikleri gibi güvenlik ve servis kolaylığı için kullanılan görme tabanlı sensörler de bulunmaktadır.

Chanard vd., (2018) yaptıkları çalışmada; elastik dünya modeline dayalı olarak, yatay ve dikey yer değiştirmelerin, gözlemlenen yüzey kütle farklılıklarından türetildiğini ve bu yüzey kütle farklılıklarının da öncelikle kıtasal su depolaması, atmosferik basınç ve okyanus sirkülasyonu ile ilgili olduğunu belirtmişlerdir. Ayrıca, çalışmada diğer atipik fiziksel etkiler, GNSS gözlemleri ile yükleme modeli tahminleri arasındaki kalan farklılıkları açıklamaya katkıda bulunabileceği ortaya çıkmaktadır .

Xiao vd., (2019) yaptığı çalışmada; deformasyon sürecinin dolgu malzemesinin homojenliği, su seviyesi ve sızıntıdan etkilendiği açıklamışlardır. Ayrıca çalışmada, rezervuardaki su seviyesi ile baraj yüzeyinin deformasyonu arasında, su seviyesindeki değişikliklerin barajın deformasyonuna katkıda bulunan ana faktör olması gerektiğini gösteren önemli bir korelasyon ortaya çıkmaktadır.

Li vd., (2019) yaptıkları çalışmada; Yarı dinamik veri doğruluğunu korumak için elektronik GNSS sisteminin yarı dinamik veri ile entegre edilmesini önermişlerdir. Yarı dinamik referans noktasındaki yüzey deformasyon modeli, kontrol noktalarının gerçek zamanlı güncellenmiş koordinatlarını sağlayabilir. e-GNSS'den gözlemlenen koordinatların zaman serileri ile yüzey deformasyon modelinden hesaplanan koordinatların zaman serileri arasındaki karşılaştırma, yarı dinamik referans noktasında yüzey deformasyon modelinin doğruluğunun izlenmesine yardımcı olmaktadır

Bu çalışmada, baraj deformasyonlarının sebepleri, nasıl gerçekleştiği ve deformasyon izlemede GNSS araçlarının kullanımı araştırılmıştır. Ayrıca, baraj derformasyonları Irak’ta yer alan Al Kut Barajı örneğinde incelenmiştir.

\section{MATERYAL ve METOT}

Çalışmada, deformasyonu izlemek ve ölçmek için Irak'ın Wasit ilindeki Al Kut Barajı seçilmiştir. Wasit ili, Irak-İran sınırında, depreme maruz kalan levhaların birleştiği noktada yer almaktadır. Şekil 1'de Wasit ilinin konumu gösterilmektedir.

Al Kut Barajı, Bağdat'ın 180 km güneyinde, Dicle Nehri kıyısındaki Al Kut şehrinde bulunmaktadır. Irak'taki en uzun barajlardan biridir. Baraj, 1939'da İngilizlerin gözetiminde inşa edilmiştir. Elektrik üretmek için kullanmanın yanı sıra su depolamaya da katkısı nedeniyle Irak'ın önemli barajlarından biri olarak kabul edilmektedir. Al Kut Barajı, Dicle Nehri üzerindeki en önemli sulama tesislerinden biridir, çünkü bu baraj, suyun Irak'ın güneyindeki illere dağıtımını sağlamakta ve illerdeki tarım projeleri için sulama imkânı sunmaktadır. 550 metre uzunluğunda olan Al Kut Barajı, her biri 6.00 x 6.50 m boyutlarında, 56 adet manuel ve elektrikle çalışan dikey kapılardan oluşmaktadır. Şekil 2'de Al Kut barajına ait bir görüntü sunulmuştur.

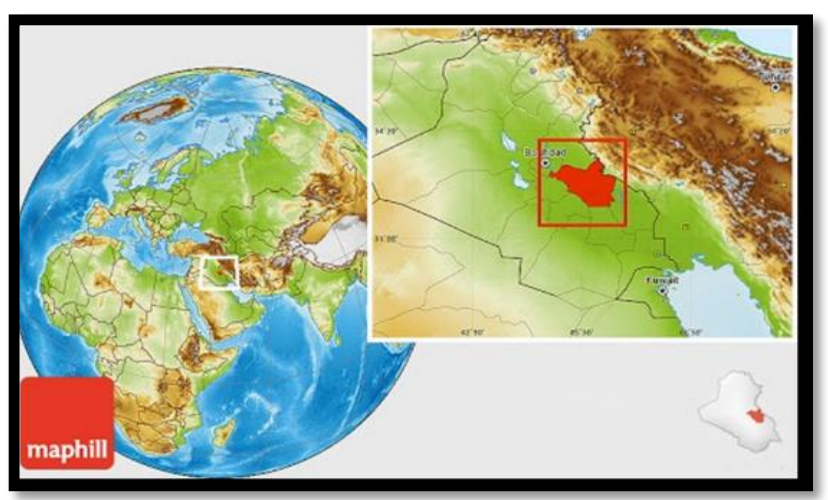

Şekil 1. Wasit ili konumu.

Figure 1. Wasit province location.

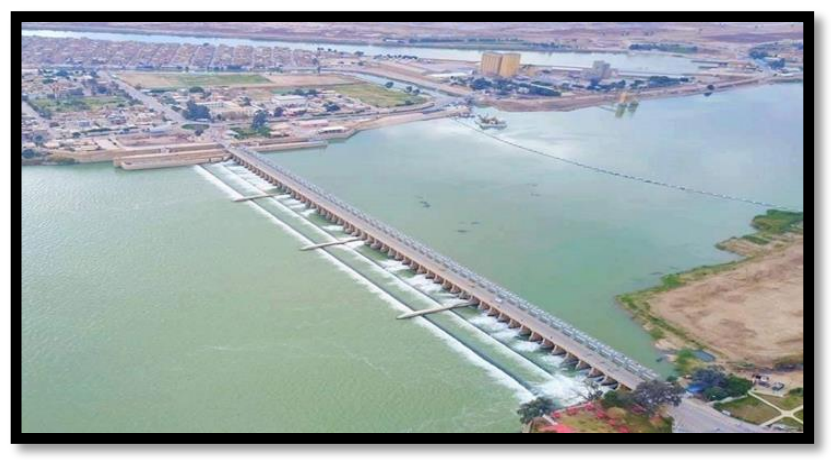

Şekil 2. Kut Baraj1.

Figure 2. Kut Dam.

GPS ve Nivo cihazı ile ölçümler gerçekleştirilmeden önce, baraj dışındaki sabit temeller veya platformlar üzerindeki referans istasyonları için uygun noktaları seçmek ve baraj üzerindeki izleme noktalarını belirlemek için çalışma alanı ziyaret edilmiştir. Barajda, nivo kullanarak dikey izleme noktaları ve DGPS kullanarak yatay izleme noktaları olmak üzere iki takım gözlem noktası belirlenmiştir. Belirlenen noktalarda beton çivilerle tutturulmuş işaretleyiciler aracılığıyla ayırt edici gözetleme noktaları kalıcı hale getirilmiştir. İzleme noktalarının mekânsal kontrolleri Wasit Valiliği ve $\mathrm{Su}$ Kaynakları Bakanlığı ile koordineli olarak gerçekleştirilmiştir. Sabit referans için kalıcı bir izleme noktası tanımlanmıştır.

DGPS notları, TOPCON TOOL yazılımı kullanılarak bilgisayar sistemi klasörüne indirilmiş, indirilen veriler işlenip ve düzeltilip gerçek koordinatlara dönüştürülmüş ve çizilmek üzere AutoCAD programına aktarılmıştır. Şekil 3'te, GPS cihazının sabit noktasının (Best) konumunu ve bir Rover cihazı ile barajın merkezindeki deformasyonu izlemek için kullanılan diğer nokta gösterilmektedir. 


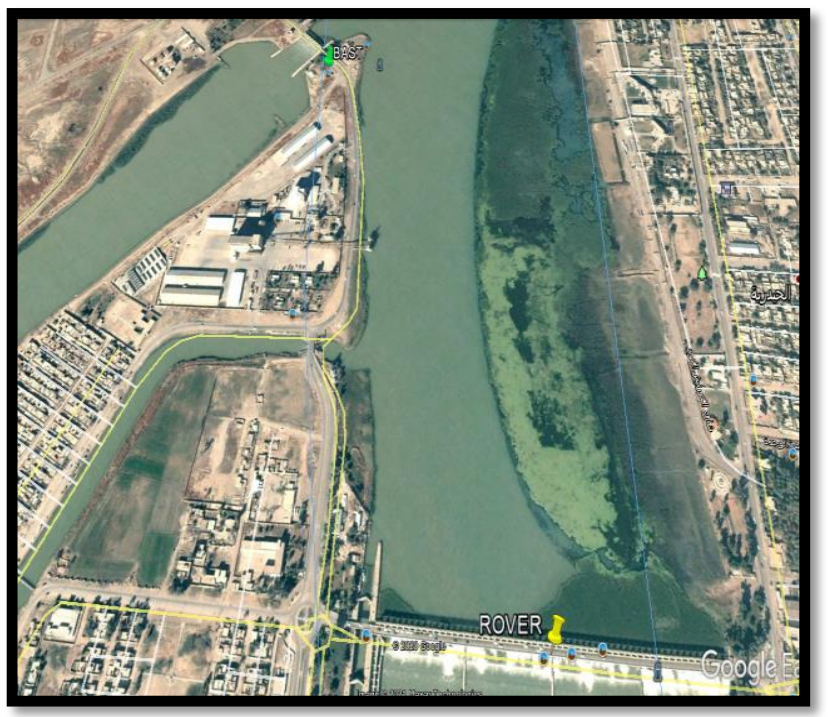

Şekil 3. Sabit noktanın (Best) ve Rover cihazı ile barajın merkezindeki deformasyonu izlemek için kullanılan diğer noktanın konumu.( Google Earth, 2020)

Figure 3. The location of the fixed point (Best) and the other point used to track the deformation in the center of the dam with the Rover device.

Olası yer değiştirmeyi izlemek ve ölçmek için $\mathrm{Al}$ Kut Barajı jeodezik ağ izlenerek Su Kaynakları Bakanlığı / Etüt Genel Müdürlüğü tarafindan periyodik olarak kontrol edilir. $\mathrm{Bu}$ ağ, baraj yüzeyine yerleştirilmiş kolonlardan oluşmaktadır. Bu çalışma, yüksek ölçüm doğruluğuna ulaştığı için GPS kullanılarak yatay deformasyonun düzenli izlenmesini ve nivo kullanılarak dikey seviyelendirmeyi sağlamaktadır. Çünkü baraj deformasyon süreci yavaştır ve kısa sürede ya da doğruluğu düşük cihazlarla gerçekleştirilememektedir.

Geleneksel araştırmalar bir "görüş hattı" gerektirmektedir ve sürekli gözetimsiz saha operasyonları (yüksek örnekleme oranları ve entegre ağ bağlantıları kullanarak) GPS kadar uygun değildir. Geleneksel ölçme sistemlerinde verilerin silinmesi GPS ile karşılaştırıldığında daha az karmaşık olsa da, yüksek hassasiyetli GPS analizinin güvenilir otomasyonu artık makul ölçüde rutin hale gelmiştir.

Çalışmada, detaylı yatay konumsal bilgileri sürekli doğrulukla elde etmek için GPS sistemi kullanılmıştır. Kullanılan Leica GPS sistemi, yatay: $2 \mathrm{~mm}$ $+0,5$ ppm' ye kadar sürekli bir çözünürlükte ayrıntılı yatay konum bilgileri elde etmek için kullanılmaktadır. Yüksek doğrulukta sonuçları elde etmek için uzun süreli gözlemlerden yararlanılmış, üç yıllık bir dönem için (20172018-2019) yıllık gözlemler yapılmıştır. Tüm gözlemler, her nokta için iki saatlik bir süre boyunca her yılın Eylül ayında gerçekleştirilmiştir. Barajın su seviyesinin düşmesi ile barajın deformasyonu arasında doğrudan bir iliş̧ki bulunmaktadır. Barajdaki su seviyesi azaldığında, barajın tepesindeki noktalar kaynağa doğru kayma eğilimindedir. Ters hareket durumunda, baraj eksenindeki noktalar aşağıya doğru kayma eğilimindedir. Bu durumda oluşacak hatanın üstesinden gelmek için noktalar ölçülmüş ve su seviyesi diğer gözlemlerden yaklaşık olarak alınmıştır. Barajda meydana gelen deformasyonu belirlemek için, çalışma yapılacak tesisten 900 metre uzakta, çalışma sahası dışında, biri sabit referans (Best) olmak üzere iki nokta seçilmiştir. Böylece, gelecekteki ölçümler yapılırken nokta, referans için güvenli bir şekilde sabitlenecektir.

Sabit referans noktası, Gerçek Zamanlı Kinematik (Real Time Kinematic (RTK)) yöntem kullanarak, izlemede kullanılan ikinci nokta ise, Rover kullanılarak belirlenmiştir. Mühendislik uygulamalarında aplikasyon ve detay alımı sirasinda noktalara ait konumların gerçek zamanlı olarak belirlenmesi gerekmektedir. $\mathrm{Bu}$ nedenle nokta konumlarını gerçek zamanl $1 \mathrm{~cm}$ mertebesinde belirleyen RTK yöntemi geliştirilmiştir (Arslanoğlu, 2002). RTK yönteminde konumu yüksek doğrulukla bilinen bir referans istasyonu ve bu istasyona en fazla $15-20 \mathrm{~km}$ kadar uzaklıkta bulunan bir ya da daha fazla gezen alıcıya ihtiyaç duyulmaktadır. (İnal vd., 2014). Şekil 4’te uydu görüntüsü üzerinde sabit nokta ve hareket noktasının konumunu gösterilmektedir..

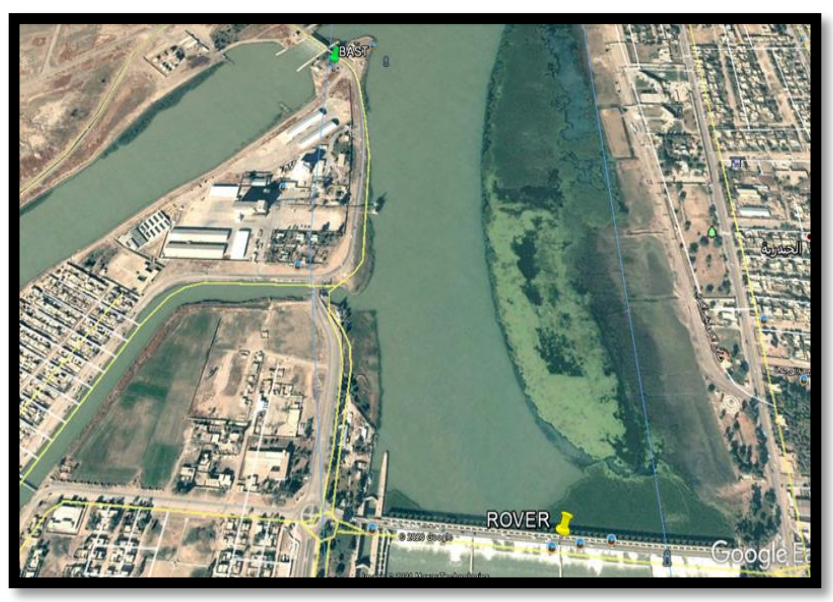

Şekil 4. 2020 yılına ait Google Earth görüntüsü üzerinde sabit nokta ve hareket noktasının konumu

Şekil 4. Position of fixed point and departure point on Google Earth image for 2020.

Her nokta GPS cihazı kullanılarak iki saat süreyle izlenmiştir. Aynı seansta RTK yöntemi ile araçların hareketinden kaynaklanan hatanın giderilmesini sağlamak için çok yüksek doğrulukta bir yatay izleme gerçekleştirilmiştir. Bu amaçla her 30 dakikada bir hareket etmeden aynı frekansta ve aynı noktada bağımsız 4 gözlem yapılmıştır. Düşey hareket ise, irtifanın doğruluğunu sağlamak, faz sistemi hatalarından ve dalgalardaki bozulmalardan etkilenmemek için dijital nivo kullanılarak belirlenmiştir.

Tablo 1'de ölçülen yatay ve dikey koordinatın üç yıllık gözleminde yıldan ylla bir fark olduğu görülmektedir. 
Tablo 1. 2017, 2018 ve 2019 y1llarında gözlemlenen noktanın koordinatları.

Table 1. Coordinates of the point observed in 2017, 2018 and 2019.

\begin{tabular}{lccc}
\hline Gözlem Tarih & Dikey koordinat & Yatay koordinat & Yükseklik \\
\hline 2017 & 3596010.215 & 576806.222 & 22.41379 \\
2018 & 3596010.216 & 576806.213 & 22.41723 \\
2019 & 3596010.223 & 576806.206 & 22.42062 \\
\hline
\end{tabular}

\section{BULGULAR VE TARTIŞMA}

Elde edilen sonuçlardan, hem yatay düzlemde hem de düşey düzlemde eşit olmayan farklılıklar gözlenmiştir. 2017 ve 2018 gözlemleri arasındaki fark, yatay düzlemde $(0.009 \mathrm{~m})$ ve düşey düzlemde $(0.00344 \mathrm{~m})$ olarak belirlenmiştir. 2018 ile 2019 yılları arasındaki fark ise yatay düzlemde $(0.007 \mathrm{~m})$ ve düşey düzlemde (0.00339 m) olmuştur. 2017 yılında yapılan ilk gözlem ile 2019 yılında yapılan son gözlem arasındaki fark ise yatayda $(0,016 \mathrm{~m})$ ve düşeyde $(0,00683 \mathrm{~m})$ olarak belirlenmiştir.

Yatay koordinatlardaki farkın (izleme ile sonraki arasındaki kayma ve bozulma), AutoCAD programındaki görünümü Şekil 5'te gösterilmiştir.

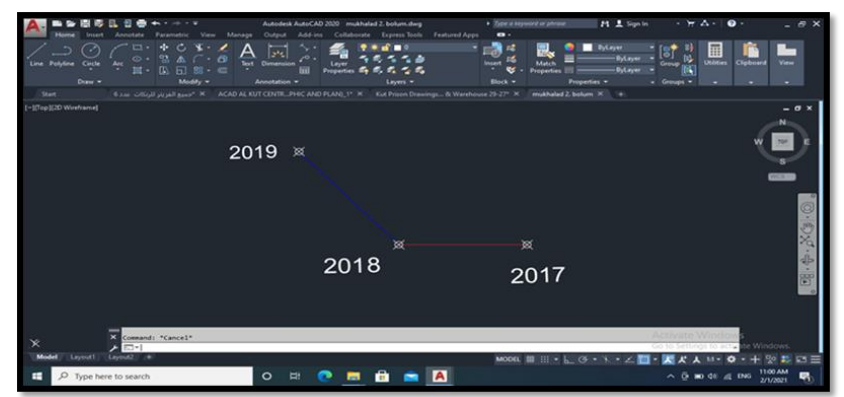

Şekil5. AutoCAD programına göre gözlemlenen noktaların konumlarındaki fark.

Figure 5. The difference in the positions of the observed points according to the AutoCAD program.

Kısmi taşıyıcı faz önyargısı ve uydu saat varyasyonunu içeren uydu sinyaline bağlı hata koşulları giderilmiştir. Ardından düşük gürültüleri sayesinde ham taşıyıcı çift fazlı sinyaller olarak L1 ve B1 kullanılmıştır. Gecikmenin dağılmamasını sağlamak için $15^{\circ}$ 'lik bir dar açı kullanılarak elimine edilen yayılma ortamı ile ilgili hata koşullarının yanı sıra çift farklılıkları gözlemleyerek hafifletilmiştir.

Noktanın gözlem tarihlerine göre yıllara göre yer değiştirmeleri 2017-1018 yılları arasında $0.0091 \mathrm{~m}, 2018$ 2019 yılları arasında, $0.0099 \mathrm{~m}$ ve 2017-2019 yıllarına bakıldığında ise $0.0179 \mathrm{~m}$ olduğu görülmektedir. $\mathrm{Bu}$ deformasyona barajın taban seviyesindeki sıcaklık fark1, deprem gibi doğa olaylarının yanı sıra, yapı malzemeleri, su akışının hızı ve yönü de neden olmaktadır. Tablo 2'de gözlem yapılan noktanın yıllar arasındaki mesafe farkı gösterilmiştir.
Tablo 2. Noktanın yıllar arasındaki mesafe farkı.

Table 2. Measurement difference between years.

\begin{tabular}{lc}
\hline Gözlem Tarihi & Mesafe Fark (m) \\
\hline $2017-2018$ & 0.0091 \\
$2018-2019$ & 0.0099 \\
$2017-2019$ & 0.0179 \\
\hline
\end{tabular}

Tablo 3.'de ölçüm yapılan noktadaki yıllar arasında gözlem farkı verilmiştir. Tablo 3'ten de görüleceği üzere, 2017-2019 yılları arasında dikey koordinat farkı $0.008 \mathrm{~m}$, yatay koordinat fark1 $0.016 \mathrm{~m}$, yükseklik farkı ise 0.00683 $\mathrm{m}$ olarak belirlenmiştir.

Tablo 3. Ölçüm yapılan noktadaki yıllar arasındaki gözlem farkı. Table 3. Observation difference between years at the measurement point.

\begin{tabular}{lccc}
\hline $\begin{array}{l}\text { Gözlem } \\
\text { Tarihi }\end{array}$ & $\begin{array}{c}\text { Dikey koordinat } \\
\text { farkı }(\mathbf{m})\end{array}$ & $\begin{array}{c}\text { Yatay koordinat } \\
\text { farkı }(\mathbf{m})\end{array}$ & $\begin{array}{c}\text { Yükseklik farkı } \\
(\mathbf{m})\end{array}$ \\
\hline $2017-2018$ & 0.001 & 0.009 & 0.00344 \\
$2018-2019$ & 0.007 & 0.007 & 0.00339 \\
$2017-2019$ & 0.008 & 0.016 & 0.00683 \\
\hline
\end{tabular}

Yatay ve dikey eksenlerdeki koordinat farkları karşılaştırıldığında; dikey yöndeki koordinat farklarının, yatay yöndeki koordinat farklarının yaklaşık iki katı olduğu ve bunun sonucunda da su akış yönünün dikey yöne paralel olduğu söylenebilir. Şekil 6'da gözlem yapılan noktanın yıllar içinde ölçülen değerlerinin farkı grafik olarak gösterilmiştir.

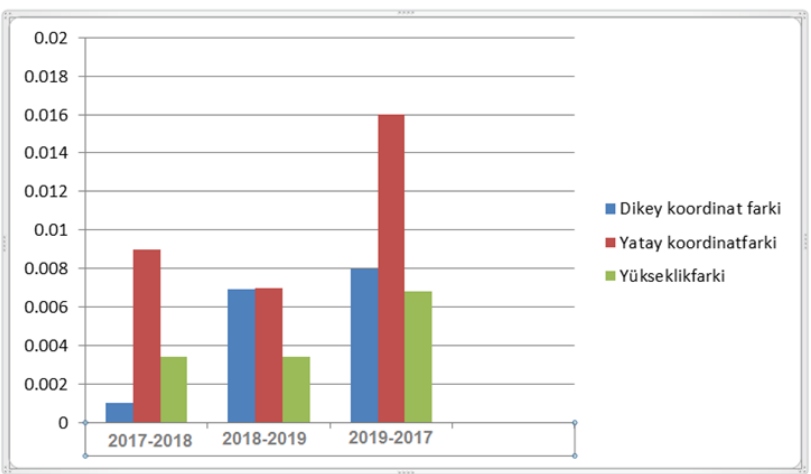

Şekil 6. Gözlem yapılan noktanın yıllar içinde ölçülen değerlerinin fark grafiğii.

Figure 6. The difference graph of the measured values of the observed point over the years.

\section{SONUÇLAR VE ÖNERILER}

Sonuç olarak çalışmada Irak'ın Wasit ilindeki Al Kut Barajındaki deformasyon GNSS araçları kullanılarak incelenmiştir. İncelenen sonuçlara göre, hem yatay düzlemde hem de düşey düzlemde eşit olmayan farklılıklar gözlenmiştir. Deformasyondaki bu farklılıkların nedenlerinin aşağıdaki doğal ve fiziksel faktörlerden kaynaklandığı düşünülmektedir;

- Doğa olayları (2017 yılında İran'da meydana gelen $(7,6)$ büyüklüğündeki deprem, yatay düzlemde ve düşey 
düzlemde etkinin belirginleştiği büyük bir deformasyona neden olmuştur. $\mathrm{Bu}$ depremin, başta sınır bölgeleri olmak üzere Irak bölgelerinde de çok büyük etkisi olmuştur).

- Isı faktörü: (Barajdaki mevsimsel sıcaklık değişiklikleri)

- Yükler: (sabit ve ölü yükler)

- Su basinci ve suyun hareket yönü. (Rezervuardaki su seviyesi ile baraj yüzeyinin deformasyonu arasında önemli bir korelasyon vardır. $\mathrm{Bu}$ da su seviyesindeki değişikliklerin barajın deformasyonuna neden olan ana faktör olduğunu göstermektedir).

- Barajın beton malzemelerinin oksidasyonu ve zayıflamasıdır.

Barajların güvenliğini sağlamak ve bunları büyük bir finansal maliyet veya mühendislik çabası ve çalışma tehlikesi olmadan izlemek için, baraj gövdesine sabit sensörlerin takılarak anlık değişimlerinin gözlenmesi tavsiye edilmektedir. Ayrıca hidrolik yapının farklı bölümlerindeki dolgu malzemeleri de dikkate alınması gerekmektedir.

\section{KAYNAKLAR}

Abdulkahdum, A. (2015). A comparison of National Orthometric Height with DGPS/Levelling and ITRF 00 Datum with WGS 84 (08) Geoid. International Journal of Advancement in Research and Technology, 4(11).

Abdullahi, I. \& Yelwa, N. (2016). Structural Deformation Monitoring Surveys of New Administrative Building of Federal School of Surveying, OyoNigeria, International Journal of Science and Technology, 6(1), 1-14.

Al-Husseinawi, Y., Li, Z., Clarke, P. \& Edwards, S. (2018). Evaluation of the stability of the Darbandikhan Dam after the 12 November 2017 Mw 7.3 Sarpol-e Zahab (Iran-Iraq border) earthquake. Remote Sensing, 10(9), 1426. DOI: $10.3390 / \mathrm{rs} 10091426$

Anastasiadis, A., Klimis, N., Makra, K. \& Margaris, B. (2004,). On seismic behavior of a $130 \mathrm{~m}$ high rockfill dam: An integrated approach. Proceedings of the 13th World Conference on Earthquake Engineering, 1-6 Ağustos 2004, Vancouver, BC, Canada, 2933.

Barzaghi, R., Cazzaniga, N. E., De Gaetani, C. I., Pinto, L. ve Tornatore, V. (2018). Estimating and comparing dam deformation using classical and GNSS techniques. Sensors, 18(3), 756. DOI: 10.3390/s18030756

Burgmann, R. \& Dresen, G. (2008). Rheology of the lower crust and upper mantle: Evidence from rock mechanics, geodesy, and field observations. Annual Review of Earth and Planetary Sciences, 36, 531567.

DOI:
Galán, D., Marchamalo, M., Martinez-Marin, R. \& Sánchez-Sobrino, J. (2013). Geomatics applied to dam safety DGPS real time monitoring. International Journal of Civil Engineering, 11(2), 134-141.

Hill, C.D. \& Sippel, K.D. (2002). Modern Deformation Monitoring: A Multi Sensor Approach. FIG XXII International Congress. 19-26 Nisan 2002. Washington, D.C. USA, 1-12.

Jansen, R.B. (1983). Dams and public safety: A water resources technical publication. US Government Printing Office.

Kalkan, Y., Alkan, R.M. \& Bilgi, S. (2010). Deformation monitoring studies at Atatürk Dam. FIG Congress 2010 Facing the Challenges - Building the Capacity, 11-16 Nisan 2010 Sydney, Australia, 1-14.

Li, C.K., Ching, K.E. ve Chen, K.H. (2019). The ongoing modernization of the Taiwan semi-dynamic datum based on the surface horizontal deformation model using GNSS data from 2000 to 2016. Journal of Geodesy, 93(9), 1543-1558. DOI: 10.1007/s00190019-01267-5

Moore, J.F., (1992). Monitoring building structures. Springer, London.

Rodrigues, M., Oliveira , S., Lima, J.N. ve Proença, J., (2020). Displacement Monitoring In Cabril Dam Using GNSS. Fourth International Dam World Conference, 21-25 Eylül 2020. Lisbon, Portugal, 118.

Okiemute, E.S, Ono, M.N. \& Olujimi, O.F. (2018). Monitoring and Analysis of Vertical Deformation of Palm House Benin City Using Digital Level. International Journal of Advances in Scientific Research and Engineering (ijasre) 4(9), 6-14. DOI: 10.31695/IJASRE.2018.3286

Park, H.S., Lee, H., Adeli, H. \& Lee, I. (2007). A new approach for health monitoring of structures: terrestrial laser scanning. Computer-Aided Civil and Infrastructure Engineering, 22(1), 19-30. DOI: 10.1111/j.1467-8667.2006.00466.x

Radhakrishnan, N. (2014, ). Application of GPS in structural deformation monitoring: A case study on Koyna dam. Journal of Geomatics, 8(1), 48-54.

Sêco e Pinto, P.S. (2010). Understanding Seismic Embankment Dam Behavior Through Case Histories. International Conferences On Recent Advances In Geotechnical Earthquake Engineering And Soll Dynamıcs (s.1-27). San Diego, California.

Taşçi, L. (2008). Dam deformation measurements with GPS. Geodezija ir kartografija, 34(4), 116-121. DOI: 10.3846/1392-1541.2008.34.116-121

USACE. (2002). Engineering and design-Structural deformation surveying. Department of the Army US Army Corps of Engineers Washington DC.

Xiao, R., Shi, H., He, X., Li, Z., Dongzhen, J. \& Yang, Z. (2019). Deformation monitoring of reservoir dams using GNSS: An application to south-to-north water diversion project, China. IEEE Access. 7, 5498154992. DOI: 10.1109/ACCESS.2019.2912143.

Yıldırım, A.F. (2007). Mühendislik yapılarının deformasyon analizinde GPS ölçülerinin kullanılabilirligi. Yüksek Lisans Tezi, Selçuk Üniversitesi Fen Bilimleri Enstitüsü. Konya, Türkiye, 76s. 